\title{
Prevalence of back pain among fulltime United States workers
}

\author{
J P LEIGH, ${ }^{12}$ R M SHEETZ ${ }^{3}$ \\ From the Department of Economics, ${ }^{1}$ San Jose State University, San Jose, CA 95192-0114, and Department of \\ Medicine, ${ }^{2}$ HRP Building, Stanford University Medical Center, Stanford, CA 94035, and Deloitte, Haskins and \\ Sells, ${ }^{3}$ Lexington, Kentucky, USA
}

ABSTRACT A source of data on the health and working conditions of a probability sample of United States workers, the Quality of Employment Survey for 1972-3 (QES73), is investigated for the first time to determine which groups of workers are more or are less likely to report back pain. Estimated coefficients from a logistic regression are used to calculate odds ratios and confidence intervals for various groups. Few previous studies on back pain among United States workers control for as many potentially confounding variables as are considered in this study and few use data from a national probability sample of workers. The following independent variables are judged to be important positive correlates based on their estimated odds ratios and confidence intervals: farm, service, blue collar, and clerical work; low levels of schooling and income; jobs needing physical effort; age between and including 50 to 64 ; and smoking. Marital separation was found to be negatively correlated with back pain. Caution should be exercised in attempting to generalise these findings, since the back pain variable is based on respondents' subjective evaluations. Moreover, the variable does not distinguish between lower or upper back or neck pain, nor is information on the duration or frequency of pain available.

Back pain represents a significant problem for workers and employers ${ }^{1-13}$ and back injuries produce approximately $19-25 \cdot 5 \%$ of all workers' compensation claims. ${ }^{510}$ In addition to the severity of the problem, the burden of suffering from back pain is not equally shared by all workers. The greatest frequency for back pain among workers has been reported to occur between the ages of 35 and $55 .^{4}$ No consensus has emerged concerning the relative risks faced by men versus women or blacks versus whites, yet workers' compensation claims for back pain are more often filed by men than women. ${ }^{9}$ Workers found to be at greater risk for back pain include those who are tall, obese, divorced, separated or widowed, and who completed only a few years of schooling. ${ }^{4}$ Activities reported to be associated with increased risk of back pain include overexertion in association with lifting, bending, or pulling ${ }^{4510}$; prolonged static work position ${ }^{4}$; and heavy physical labour. ${ }^{3}$ Readers seeking a comprehensive review of the epidemiology of back pain are referred to Kelsey. ${ }^{13}$

A recent review of back pain among employees by

Accepted 26 September 1988
Anderson listed 136 studies, most of which were based on data from countries other than the United States. ${ }^{4}$ Whereas many epidemiological studies of back pain have relied on United States data, the data have typically been for the adult population at large, not just for working individuals. Moreover, a search did not find any United States study on workers which used a multivariate statistical design.

The present study contains results from a national sample of workers, widely used by economists and sociologists but not by epidemiologists. This study assesses the magnitude and distribution of self reported prevalence of back pain among selected occupational groups. The following independent variables are considered as possible correlates of back pain: age, race, gender, income, schooling, marital status, height, weight, smoking status, occupation involving heavy labour or repetition or both, and broad occupational groups.

\section{Materials and methods}

A national survey of the quality of employment (QES) was conducted in January and February 1973 by the 
survey research center of the Institute for Social Research at the University of Michigan. The survey was directed by the Employment Standards Administration, United States Department of Labor, and the National Institute for Occupational Safety and Health, and was the second undertaken by the investigators to provide an overview of working conditions in the American labour force.

Details of the sample selection have been published. ${ }^{14}$ There were 1496 respondents from around the country, excluding Alaska and Hawaii. The requirements for respondent eligibility were that they be at least 16 years old and work for pay 20 or more hours a week. The sample was, therefore, not representative of all workers but only of those employed 20 or more hours a week. Information was sought about the impact of work on the worker in terms of such things as satisfaction, physical health, and financial well being. The data have been used by labour economists ${ }^{15}$ and industrial psychologists ${ }^{16}$ but, to date, have not been widely cited by epidemiologists. An exhaustive account of the rich detail available in the QES is available in Quinn et al..$^{14}$

Not all of the 1496 respondents are considered in the analysis that follows. Some 82 individuals are excluded due to missing data-for example, some individuals did not offer intelligible answers to some of the questions used in the subsequent analysis. The relevant sample size is thus reduced to 1414 .

The back pain variable was constructed using answers to the following question: "Have you had trouble with your back or spine in the past year?" Two hundred and eight respondents answered "yes" and were given a one for the back pain variable; 1134 respondents answered "no" and were given a zero. The question contains limited information. It did not distinguish among upper or lower back or neck pain. Duration and frequency also are unknown.

It should first be pointed out that roughly $20 \%$ of the QES sample reported back pain. The $20 \%$ figure compares favourably with the $18 \%$ prevalence figures in the widely cited study by Nagi et $\mathrm{l}^{17}$ and the recent study by Reisbord and Greenland, ${ }^{18}$ thus lending credence to the accuracy of the responses in the QES.

Four variables appear in this study that were not considered by Reisbord and Greenland ${ }^{18}$ : height (tall), weight (obese), smoking (smoker), and job repetitiveness. The tall variable equalled one for men over 72 inches and women over 68 inches. Obese equalled one for those indicating they view themselves as being very much overweight, rather than just overweight. Smoker equalled one for current smoker. The obese and smoker variables are obviously deficient. Obese relies on a subjective evaluation and smoker lumps all smokers together whether they are light or heavy and whether they smoke cigarettes, pipes, or cigars. The variables are included in the analysis because weiglif and smoking habits have been found to be powerfui risk factors in a variety of diseases. The job repetitio variable equalled one for those stating that their jobs required "a lot" as opposed to a "moderate amount or "only a little" repetition.

Two techniques were used to assess correlates of back pain. The first involves the presentation of descriptive statistics and calculation of chi-squares of the variables pertaining to gender, race, schooling, anf so on. Simple associates were sought between, fơp example, sex and the prevalence of back pain withou $\vec{b}$ taking account of the types of jobs men and woment have. The chi-squared analyses should be viewed $\overrightarrow{\alpha 8}$ preliminary since they do not control for confounding variables.

To add additional insight into the correlates of back pain, a logistic regression was run on the data in whicf the binary variable back pain was treated as the dependent variable and sex, race, marital status, an $\$$ so on were treated as independent variables. The independent variables are entered as binary variable $\underline{\hat{s}}$ so that odd ratios may be calculated using estimated logistic coefficients. ${ }^{19}$

The recent study by Reisbord and Greenland waథ used as our guide in specifying which independen variables should enter the equation. ${ }^{18}$ Virtually all os the variables they included in their study were included in ours. We go beyond Reisbord and Greenlandog considering height and smoking as possible correlates of back pain.

There is some controversy surrounding the deters mination of which variables are important in a logistie regression. The traditional approach looks only at the $p$ value for the coefficient. If the $p$ value is equal to of less than 0.05 the variable is judged to be important $b \overrightarrow{\vec{B}}$ virtue of its statistical significance. Recent author such as Gardner and Altman argue that the traditiona要 view has three glaring weaknesses ${ }^{20}$ : (1) The selection. of $p<0.05$ is arbitrary. A coefficient estimate could yield a $p=0.08$ but be automatically regarded as unimportant even though the estimate would produce an estimated odds ratio of, say, 5·0. (2) The traditionaf. criteria ignore the mean estimated effect. Suppose the estimated odds ratio and $p$ value for smoking are $4 \cdot \overline{\mathcal{Q}}$ and $0 \cdot 04$, respectively, and for male height over 72 inches and female height over 68 inches are 2.0 and 0.02 , respectively. The traditional criteria, giving aIP the weight to the $\mathrm{p}$ value, would rank height ove smoking as a risk factor. But clearly, the estimatedP odds ratio should matter since it is $\mathbf{4}$ for smokers buf only 2 for men over 72 inches and women over $68 \mathrm{~W}$ inches tall. (3) The problem of type 2 errors is treatedb too lightly. A decision rule based on $p<0.05$ allows for a greater chance of a type 2 error than a rule basec on, say, $\mathrm{p} \leqslant 0 \cdot 10$. Physicians are often willing to risk 
high probability of a type 1 error if the patient's life is at stake.

Gardner and Altman argue that both the estimated size and precision of the odds ratio should matter. They point out that information about the precision of an estimate as measured by the standard errors is most usefully presented in a confidence interval rather than a $p$ value. A confidence interval focuses attention on the estimated size of the odds ratio and the most reasonable range of estimates that should surround the true population odds ratio. They do not suggest any particular rule to assess the importance of an independent variable but note, however, that intervals with more values above than below 1 are more desirable than intervals with more values below 1 for variables assumed to be positively associated with the dependent variable. They also recognise that $p$ values are not entirely useless since the smaller the $p$ value, the less likely the interval will contain values below 1 .

But a complete reliance on confidence intervals and odds ratios ignores the important question raised in a hypothesis test: Do the data suggest that the true population odds ratio is greater than one? Could the observed sample estimate of an odds ratio be greater than 1 simply as a matter of chance?

There does not yet appear to be a consensus among epidemiologists concerning which is the most appropriate criteria $-p$ values, odds ratios, or confidence intervals. The methodological strategy used here, consequently, is to present information on all three and rely on our judgement to assess the most important correlates.

Stepwise regression is not relied on to determine whether an independent variable is important since stepwise regression, whether forward or backward, suffers two serious drawbacks identified by Cassidy, ${ }^{21}$ and Leigh ${ }^{22}$ : (1) the signs of the estimated coefficients at intermediate or final stages of the stepwise routine may be incorrect and (2) stepwise procedures may result in the exclusion of a relevant variable that was excluded just because of the arbitrary order in which the selection takes place (according to the contribution to the $\mathbf{R}^{2}$ or the chi-square). Nevertheless, in results available from the authors, a forward stepwise procedure was run on the data and the results concerning the important correlates were not altered.

\section{Results}

\section{UNIVARIATE ANALYSES}

Table 1 presents descriptive statistics and calculated chi-squares on selected variables, most of which were statistically significant, extracted from the QES. A larger version of table 1 , available from the authors, indicates all variables whether or not they were statistically significant. The list of possible correlates
Table 1 Descriptive statistics and calculated chi-squares on selected variables

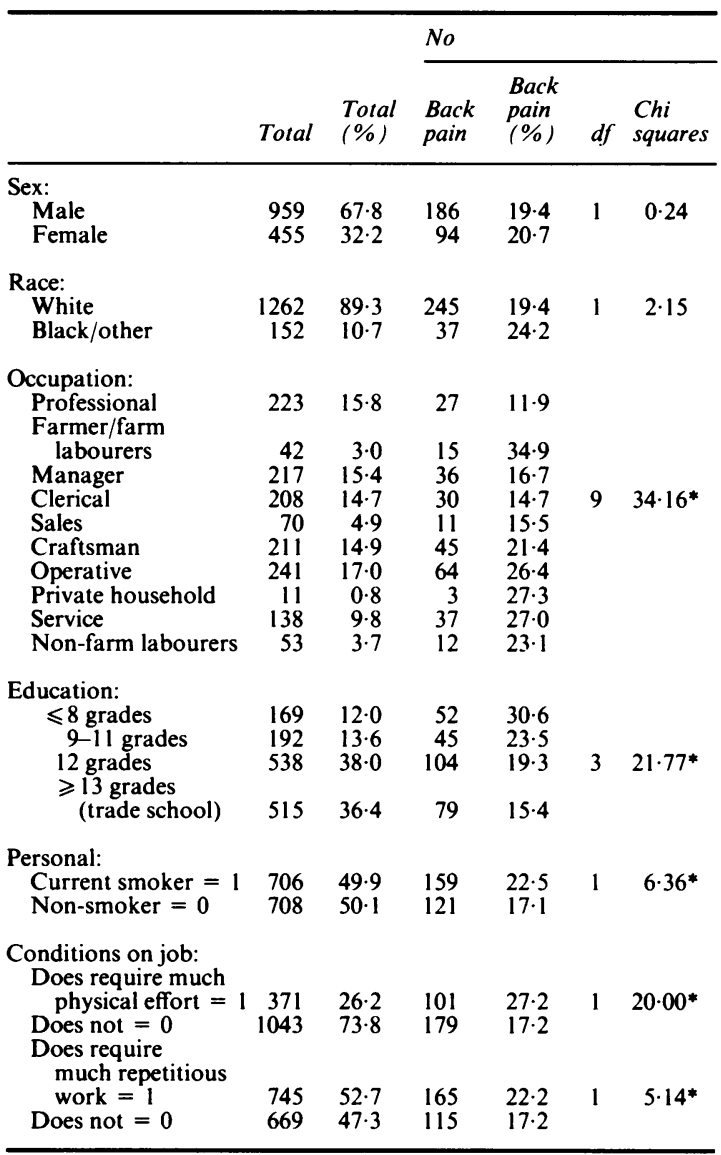

$* \mathrm{p}<0.05$.

Results on marital status, age, income to respondent, obesity, and being tall are available from the authors.

closely follows the list in Reisbord and Greenland ${ }^{18}$ except that the table 1 list includes more than that of Reisbord and Greenland. The additional variables include measures of height (tall), weight (obese), information on the smoking habit (smoker), and information on repetitive nature of the job.

Table 1 shows some interesting patterns. Fewer than $1 \%$ more women than men report back pain in the QES sample, whereas $24.3 \%$ of non-whites, but only $19.4 \%$ of whites, report back pain. In part, the race disparity could be due to the disproportionate number of non-whites in production jobs and low schooling categories. Subjects who never married have the highest prevalence of back pain, whereas widowers (male and female) report the lowest in the marital status category. Although these results would not be 
expected in a sample including non-working and retired subjects, it could be that a self selection phenomena is at work. Widows who elect to work may be a particularly healthy group since many widows with children would receive social security benefits if their husbands had been working before death, as would be the case for most women in 1973.

Age categories provide clues for the prevalence of back pain. Whereas only a narrow $(0 \cdot 9)$ difference exists between the mean per cents for 18-34 years and 35-49 years, workers in the 50-64 years category suffer the most and in the 65 years and over category suffer the least. The patterns for the 50 and over groups are easily explained. The 50-64 category is the oldest category of workers in the preretirement years. Most of these workers, younger than 62 , cannot retire with social security (unless they are disabled), and hence must work. They suffer a disproportionate amount of back pain because of their age. The 65 and over group are unique. Most, if not all, could retire with social security, but do not choose to. A strong healthy worker effect keeps their prevalence low. The age variable does not achieve statistical significance at the 0.05 level, perhaps due to the relatively few workers (33) in the 65 and over group.

There appears to be a negative association between income and back pain in the univariate results. The greatest per cent occurs in the $\$ 5000$ or less group and the least in the over $\$ 20000$ group. In part, this result could reflect reverse causality. People with back pain may earn less because of their pain. Alternatively, it may be that the incomes reflect the jobs so that low income indirectly measures production work and high income, professional work. A multivariate design is, therefore, required to consider further the association between income and back pain.

QES respondents were asked to evaluate their own weight by stating whether they were obese, overweight, right weight for height, thin, or skinny. Roughly $1 \cdot 7 \%$ stated that they were obese. A respondent's actual weight, although preferred, was not recorded by QES interviewers. Because the obese variable relies on subjective evaluations, it is open to various criticisms so that results on the obese variable should be viewed with caution. It is used simply because it is the only measure of weight in the QES. For the $1.7 \%$, obese $=1$ and for the $98.3 \%$ obese $=0$. Only a slight $1 \%$ difference in the prevalence of back pain was observed between the obese and the not obese groups.

The tall variable equalled 1 for men who stated that they were taller than 72 inches and 1 for women taller than 68 inches. Roughly $23 \%$ of tall people so classified reported back pain whereas $19 \cdot 5 \%$ of "not tall" people reported back pain.

Whereas the descriptive results for the variables of sex through to obese and tall are suggestive they must nevertheless be critically viewed. None of the differ ences in variables mentioned, sex through to obese and tall, were statistically significant at the 0.05 leve?: Variables that did achieve statistical significan $\overrightarrow{g_{5}}$ include occupation categories, education, smoking status, and conditions on the job.

It appears that white collar workers (professionalomanagers, sales workers, and clerks) suffer less an blue collar workers (craftsmen, operatives, ang labourers) and service workers more back pain. pronounced education effect is also apparent. The fewer the years of schooling, the greater the chance of back pain complaints and the more the years $\bar{\phi}$ schooling, the less the chance of complaints. The smoker variable measured current smoking status Smokers equalled 1 for people stating that the currently smoke and 0 otherwise. No QES informa tion was available on quantity smoked. Being smoker, however, may put workers at increased risk \& back trouble.

The univariate results also suggest that both jo $\underline{b}$ conditions are associated with increased frequency of back pain. Employees in jobs requiring "lots of physical effort and "lots of" repetitious work repoc more back pain than employees not holding job requiring physical effort and repetitious work.

As with all univariate analyses, the search for simpte associations is limited. Multivariate analyses girfo required so that the effects of confounding are minimised.

\section{LOGISTIC REGRESSION}

Table 2 presents the results on estimated odds ration and $95 \%$ confidence intervals derived from estimate coefficients and standard errors produced by a logist regression explaining the log-of-the-odds of back pain In the interest of brevity table 2 presents only resule on selected variables. Results on all the variables are available from the authors.

The chi-squared statistic from the logistic regres sion, 188, is greater than the critical chi-squared indicating that at least one of the explanatory variq bles is making a statistically significant contributio 8 toward explaining prevalence of back pain.

Several interesting patterns emerge among the occupational categories, age, years of schooling, an annual wages. Estimated odds ratios are smallest for occupations most similar to professionals and man agers and largest for occupations least similar t尺 professionals and managers. The estimated odds ratios for clerical and sales workers are only $1.38 \mathrm{c}$ whereas ratios for service workers are 2.67 ; craftsmen operatives, and labourers 2.39; and farmers and farm workers $5 \cdot 17$.

The age pattern appears to be an upside-down "U. 
Table 2 Logistic regression results explaining the probability of reporting back pain

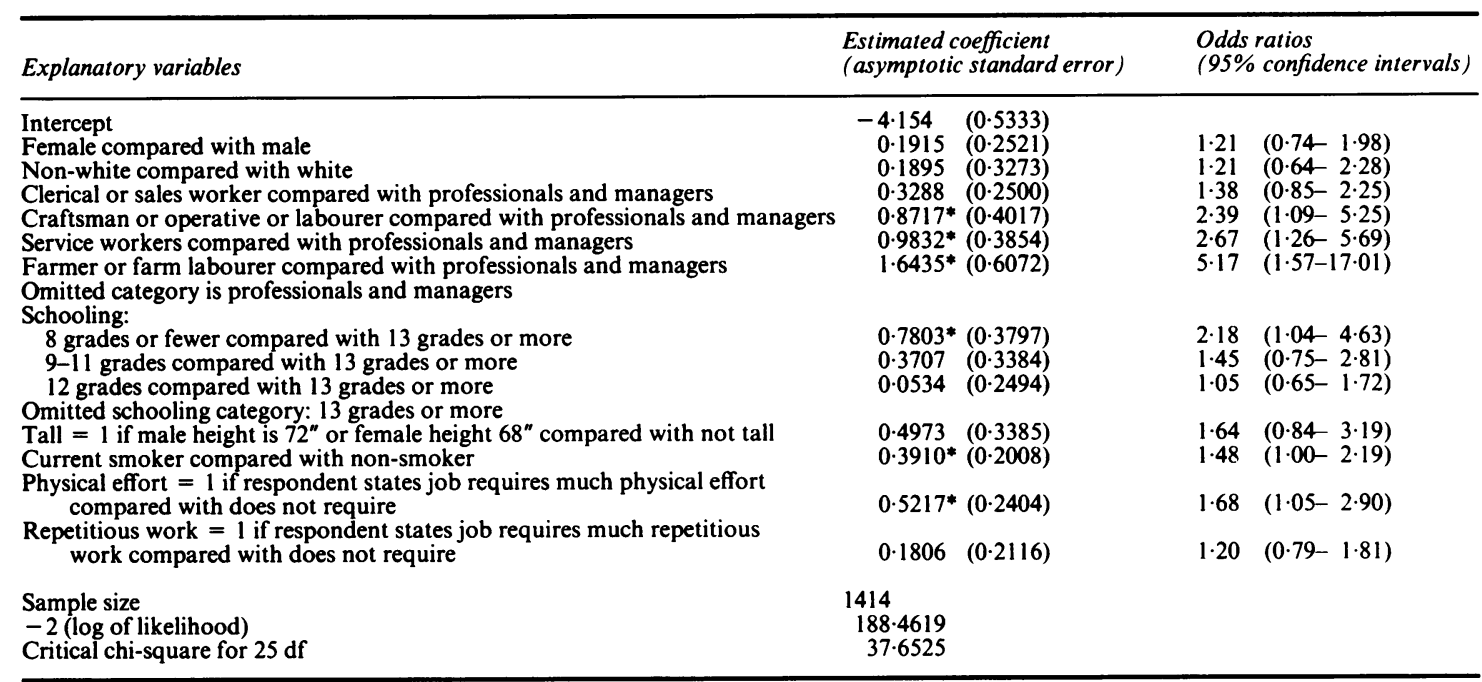

*Significant at the 0.05 level in a two tailed test.

Results on marital status, age, income to respondent, obesity, are available from the authors.

The ratios range from 1.00 for $35-49$ to 1.59 for $50-64$ and fall to 0.96 for 65 and over.

Back pain appears to be inversely related to years of schooling. The eight grades or fewer odds ratio is $2 \cdot 18$, whereas 9-11 grades drop to 1.45 and 12 grades to 1.05 .

The annual wage pattern is not as clear as the others. The ratios rise from 1.41 for $\$ 5000$ or less to 2.04 for $\$ 5001-\$ 10000$ but fall to 1.90 for the $\$ 10001-\$ 20000$ category.

To assess the most versus least important correlates of back pain, the variables with the highest odds ratio and largest lower confidence interval were selected for further scrutiny.

To assess the importance of each possible correlate, the variables were placed into two groups depending on their estimated odds ratio and the size of their lower confidence limit. Variables with large odds ratios and large lower limits were judged more likely to be important and those with small odds ratios and small lower limits were judged to be less likely important correlates of back pain. The size of the odds ratios matters, as Gardner and Altman suggest. ${ }^{20}$ The size of the lower limit matters because the larger the lower limit, the greater the $p$ value.

The variables thus classified as unlikely to have an association with back pain and their corresponding lower confidence limits (in parentheses) are the following: sex $(0.74)$, race $(0.64)$, divorced $(0.30)$, widowed $(0.54)$, never married $(0.20)$, age 35-49 $(0.62)$, age 65 and over $(0.24), 12$ years of schooling $(0.65), \$ 5000$ or less in annual wages $(0.47)$, obese $(0.21)$, and repetitious work $(0 \cdot 79)$.

The variables more likely to be associated with back pain include those with lower confidence limits either a little below or greater than one. The potentially important variables may be ranked according to their estimated odds ratios as follows (lower confidence limits in parentheses): (1) farmer and farm labourers (1.57); (2) service workers (1.26); (3) craftsmen, operatives, or labourers (1.09); (4) eight or fewer years of schooling (1.09); (5) \$5000-\$10 000 annual wages $(0 \cdot 72) ;(6) \$ 10001-\$ 20000$ annual wages $(0.70)$; (7) job needing much physical effort (1.05); (8) men taller than 72 inches and women than 68 inches $(0.85)$; (9) aged 50-64 (0.92); (10) smokers $(1.00)$; (11) 9-11 years of schooling $(0.75)$; (12) clerical or sales workers $(0 \cdot 85)$.

The separated marital status category is also included in the potentially important group but its estimated coefficient is negative, hence its lower confidence limit and odds ratio cannot be compared with the other variables.

\section{Discussion}

In agreement with the results of Reisbord and Greenland's multivariate study ${ }^{18}$ we do not find a likely effect for sex or race since neither variable is in the "more likely" group. This is in contrast with the univariate analyses in Nagi et al in which sex and race were important correlates. ${ }^{17}$ It is tempting to conclude that 
in univariate analyses sex and race variables were actually serving as proxies for employment status or schooling.

Again, as do Reisbord and Greenland and Nagi et $a l$, we find weak multivariate and univariate associations between marital status and back pain. ${ }^{18} 19$ Estimated odds ratios and prevalence proportions are less for divorced and separated individuals when compared with single people, widows, and widowers.

The importance of occupation is strongly confirmed by the results in table 2 . When compared with professionals and managers (1) craftsmen, operatives, and labourers, (2) service workers, (3) clerks and sales people, and especially (4) farmers and farm workers have significantly higher prevalence odds of back pain. The results for the disparity between blue and white collar work are consistent with those reported by Frymoyer et $\mathrm{al}^{23}$ and Andersson. ${ }^{4}$ Moreover, with the exception of the clerks and salespeople category, every other occupation category has a lower $95 \%$ confidence limit for the odds ratic greater than one.

The results for the occupation categories may reflect a causal relation. Blue collar work requires lifting, bending, pulling, and heavy physical labour, all of which have been identified as risk factors for back pain. ${ }^{3-510}$ White collar work may put less physical strain on the back.

The results for age and schooling are consistent with those in Reisbord and Greenland. ${ }^{18}$ People in the preretirement years, 50-64, suffer more back pain, other things being equal, than those aged 18 to 34 . Whereas most studies find that advancing years beyond 65 is associated with back pain, no association is found here. A simple healthy worker argument will explain this anomaly, however. People in the QES sample over 65 are full time employees. Most people older than 65 are retired. Individuals who choose to work beyond 65 are probably healthy and unlikely to suffer back pain.

The results for schooling are consistent with those published concerning the association between schooling and overall health. Grossman ${ }^{24}$ and Leigh, ${ }^{25}$ for example, find strong statistical associations between schooling and subjective measures of general health in two data sets drawn from national probability samples. Increased educational attainment was found to be associated with better health. The results in table 2 indicate a similar finding. Since the omitted category is 13 or more years of schooling, positive coefficients on the three schooling variables indicate that fewer than 13 years of schooling is associated with greater prevalence of back pain. Moreover, the size of the odds ratios drop from $2 \cdot 18$ for eight grades or fewer to 1.05 for 12 grades, again consistent with a positive relation between schooling and overall health. Whereas only the first schooling variable, eight grades or fewer, is statistically significant at better than the 0.05 level in a one tailed test, the lower confidence intervals for 9-11 grades and 12 grades are 0.75 an 0.65 , not far below 1 .

The QES data do not suggest any statisticall $\overrightarrow{\overline{\mathrm{S}}}$ significant correlation at the 0.05 level between wages and odds prevalence of back pain, again consisten with Reisbord and Greenland.$^{18}$ But two categories of wages, $\$ 5001-\$ 10000$ and $\$ 10000-\$ 20000$ were in the "more likely" group of possible correlates. The results suggest that people with the greatest earnings, $\$ 20000$ or more (in 1973), experienced less back paip than those in all other income categories. In part, this could reflect reverse causality. People who suffes severe pain may not be able to work as many hours as those who suffer no pain.

The lack of a statistically significant effect for the obese variable is, at first sight, surprising, since manto prior studies implicate obesity as a risk factor for back pain. ${ }^{4}$ But the lack of any finding present in the QES may result from the variable's construction. The obes@ variable is constructed from the subjective evaluations of the respondent's weight by the respondente Individual variation in what respondents regarded as obese resulted in a small sample size problem. Only $2 \$$ respondents in the sample of 1414 reported themselves to be obese.

The apparent lack of height as a statistically sigeo nificant variable at the 0.05 level was also unexpecte But closer examination shows that the asymptot statistic for height, 1.469 , is statistically significanta粮 the 0.10 level in a one tailed test (critical p is 1.28 ). If the $0 \cdot 10$ level is viewed as statistically significant the results for the height variable are consistent with those reported in Andersson's review of studies on back pain among workers. ${ }^{4}$

Smokers apparently report more back pain than non-smokers as the statistically significant coefficien $(p \leqslant 0.05)$ on smoker $=1$ shows in table 2 . The results are consistent with those found in Frymoyer et al. ${ }^{23} 20$

It is not clear what the causal mechanism might be linking smoking with back pain. A misplaced cigarett might require additional reaching and stooping than would otherwise occur. The correlation may also result from some unobserved third variable reflecting desire to practise healthy habits. People who smoks may be more reckless with their health than non smokers. Smokers may be more inclined than non? smokers to lift things with their backs rather than their legs, for example.

The interpretation of the results for jobs needing physical effort and involving repetitious work requires an understanding of the variable construction. If the respondent stated "lots of " physical effort demands he or she received a 1 for the physical effort variable The repetitious job variable was similarly constructed? 
Thus we expected a positive coefficient on both variables since physical effort and repetitious jobs have been found to be associated with prevalence of back pain for workers. ${ }^{4}$ Our results do not support any strong statistical association $(p \leqslant 0.05)$ between repetitious work and prevalence odds of back pain. Nevertheless, the estimated odds ratio is greater than 1 and the lower confidence interval is 0.75 . Strong statistical evidence is provided, however, for a physical effort and back pain association. The physical effort variable is significant at the 0.05 level in a two tailed test and has the expected positive sign. Moreover, the estimated odds ratio is reasonably large- $-1 \cdot 68$.

We would like to express our appreciation to Lorann Stallones, Sander Greenland, and Lesley Reisbord for helpful suggestions. This project was supported by grant number RO1 OHO2586 from the National Institute for Occupational Safety and Health.

Requests for reprints to: J Paul Leigh, Department of Economics, San Jose State University, San Jose, CA 95192-0114.

\section{References}

1 Westrin CG. Low back sick-listing: a nosological and medical insurance investigation. Scandinavian Journal of Social Medicine 1970;2:127-34.

2 Benn RT, Wood PHN. Pain in the back: an attempt to estimate the size of the problem. Rheum Rehab 1975;14:121-8.

3 Rowe LM. Low back pain in industry: a position paper. $J$ Occup Med 1979;11:161-9.

4 Andersson G. Epidemiologic aspects on low-back pain in industry. Spine 1981;6:53-60.

5 Johnston WW. Back injuries - a problem for both workers and employers. Ohio Monitor 1982;55:15.

6 McGill ML. Industrial back problems: a control program. J Occup Med 1968;10:174-8.

7 Brown JR. Factors contributing to the development of low back pain in industrial workers. Am Ind Hyg Assoc J 1975;36:25-31.

8 Nordby EJ. Epidemiology and diagnosis of low back injury. Occup Health Saf 1981;50:38-42.

9 Klein BP, Jensen RC, Sanderson LM. Assessment of workers' compensation claims for back strains/sprains. J Occup Med 1984;26:443-8.

10 Simons GR, Mirabile MP. An analysis and interpretation of industrial medical data with concentration on back problems. J Occup Med 1970;14:253-8.

11 Magora A. Investigation of the relation between low back pain and occupation. Ind Med 1970;39:31-7.

12 Kosiak M, Aurelius JR, Hatfield WF. Backache in industry. J Occup Med 1966;10:51-8.

13 Kelsey JL. Epidemiology of musculoskeletal disorders. New York: Oxford University Press, 1982.

14 Quinn RP, Mangione T, Seashore SE. The 1972-1973 quality of employment survey descriptive statistics with comparison data from the 1969-1970 survey of working conditions. Ann Arbor, Michigan: Survey Research Center, 1974.

15 Leigh JP. Sex differences in absenteeism. Industrial Relations 1983 ; 22:344-61.

16 Margolis B, Kroes W, Quinn R. Job stress: an unlisted hazard. J Occup Med 1974;16:659-61.

17 Nagi SZ, Rikey LE, Newby LG. A social epidemiology of back pain in a general population. J Chronic Dis 1973;26:769-79.

18 Reisbord LS, Greenland S. Factors associated with self-reported back-pain prevalence: a population-based study. J Chronic Dis 1985;38:691-702.

19 Greenberg RS, Kleinbaum OG. Mathematical modeling strategies for the analysis of epidemiological research. Ann Rev Pub Health 1985;6:223-45.

20 Gardner MJ, Altman DG. Confidence intervals rather than pvalues; estimation rather than hypothesis testing. $\mathrm{Br}$ Med J 1986;292:746-50.

21 Cassidy HJ. Using econometrics: a beginner's guide. Reston, VA: Prentice-Hall, 1981.

22 Leigh JP. Assessing the importance of an independent variable in multiple regression: is stepwise unwise? J Clin Epidemiol 1988; 41:669-77.

23 Frymoyer JW, Pope MH, Clements JH, et al. Epidemiologic studies of low-back pain. Spine 1980;5:419-23.

24 Grossman M. The correlation between health and schooling. In: Terleckyj N, ed. Household production and consumption. New York: Columbia University Press, 1975.

25 Leigh JP. Direct and indirect effects of education on health. Soc Sci Med 1983;17:227-34.

26 Frymoyer JW, Pope MH, Clements JH, et al. Risk factors in lowback pain. J Bone Joint Surg 1983;65-A:213-8. 